\title{
A Study on Priority of Classification System for Agro-healing Using the Analytic Hierarchy Process
}

\author{
Eunha Yoo ${ }^{1 *}$, Yumin Park ${ }^{2}$, Sun Jin Jeong ${ }^{1}$, Jae Soon $\mathrm{Kim}^{3}$, Yong Ku Kang ${ }^{1}$, and Yeo Jin Jeong ${ }^{4}$ \\ ${ }^{1}$ Senior Researcher, National Institute of Horticultural \& Herbal Science, RDA, Wanju-gun 55365, Republic of Korea \\ ${ }^{2}$ Doctoral Student, Department of Plant Resources, Gyeongsang National University, Jinju 52725, Republic of Korea \\ ${ }^{3}$ Researcher, National Institute of Horticultural \& Herbal Science, RDA, Wanju-gun 55365, Republic of Korea \\ ${ }^{4}$ Postdoctorial Researcher, National Institute of Horticultural \& Herbal Science, RDA, Wanju-gun 55365, Republic of Korea
}

\section{ABSTRACT}

Background and objective: As the 'Healing Agriculture Research and Development and Promotion Act' came into effect on March 25, 2021, social interest in agro-healing has been increasing exponentially. This study was conducted to analyze the priorities of agro-healing classification system and to provide basic data to inform policy directions and related research for the development and activation of agro-healing.

Methods: The survey data collected from 18 experts were analyzed using the analytic hierarchy process (AHP) method in determine the relative weights of the main and sub-criteria for the classification system. There were three main criteria identified: agro-healing input industry, agro-healing service industry, and agro-healing-related/derived industry. There were also 11 sub-criteria.

Results: The top three sub-criteria with the highest complex weights include "community service," "social rehabilitation" and "treatment and rehabilitation," all of which correspond to the main criterion "agro-healing service industry". In addition, the complex weights of the sub-criteria corresponding to the main criterion "agro-healing related/derived industry" are as follows: "other agro-healing support service," which ranked 4th, and "training and education institutions for agro-healing experts," which ranked 5 th when prioritizing the criteria.

Conclusion: The results of this study suggest that the main criterion to be considered first in establishing a classification system is "agro-healing service industry". Therefore, it is necessary to continue research on detailed service classifications and systems with verified validity to ensure expertise in human resources, and organization related to social purpose services in agro-healing.

Keywords: agro-healing industry, agro-healing service, analytic hierarchy process (AHP)

\section{Introduction}

The World Health Organization (WHO, 1948) defines health as not only the absence of disease or disability, but also the establishment of physical, mental, and social well-being. Aligned with the notion that health includes physical, mental, social, and spiritual aspects, healing has expanded its meaning to restore human wholeness $(\mathrm{Oh}$, 2020). This overlaps with the principles of agro-healing (Healing Agriculture Research and Development and Promotion Act, 2021), which refers to all agricultural activities that are provided for the recovery, maintenance, and promotion of psychological, social, and physical health by utilizing agricultural and rural resources.

This study was supported by the 2021 Horticultural and Herbal Science Program of the National Institute of Horticultural and Herbal Science of the Rural Development Administration (PJ01435601).

Received: November 19, 2021, Revised: November 30, 2021, Accepted: December 6, 2021

First author: Eunha Yoo, E-mail: galaxyoo@korea.kr, (1) https://orcid.org/0000-0002-5794-2600

Yumin Park, E-mail: cocoyumin@naver.com, (1) https://orcid.org/0000-0002-8483-3290

*Corresponding author: Eunha Yoo, galaxyoo@korea.kr, (10) https://orcid.org/0000-0002-5794-2600 
With the enforcement of the "Act on Research, Development and Promotion of Healing Agriculture" on March 25, 2021, the legal basis was established to promote the discovery of resources on agro-healing, as well as to develop, distribute, and commercialize programs using these resources, while providing professional workforce support. Social interest in agro-healing is increasing exponentially, and each local government is enacting and implementing agro-healing ordinances to create and promote the resources and facilities necessary for agro-healing (Jo, 2021). In this vein, there is a need for research on the detailed direction and development of Korean agro-healing (RDA, 2020), which includes both healing (human-centered spiritual, mental, and experiential activities) and cure (patient-centered scientific and technological medical practices).

Previous studies have focused on analyzing the status and characteristics of Korean agro-healing, while also establishing agro-healing experts, and preparing a plan that can be applied in Korea through the analysis of overseas agro-healing (Kim et al., 2013; Hong and Lee, 2016; Lee, 2016; Park and Kang, 2017). Agro-healing serves as both social services and health care, and includes the promotion of national health based on the plural functions of agriculture and rural areas, the realization of public values by solving social and cultural problems, changes in communities' social attitudes toward disability or disease, and support for the socially disadvantaged (Jang et al., 2021). Agro-healing also strengthens local communities and improves environmental sustainability (Garcia-Llorente et al., 2018). Considering that agro-healing has such pluralistic values, there is a need to prioritize the establishment of an agro-healing classification system to guide policy directions.

To effectively establish agro-healing, research is needed to develop more field-oriented and effective strategies. Therefore, this study aims to provide basic data that can inform the research and establishment of policy directions that can systematize and promote agro-healing. This will be achieved by establishing the priorities for developing a classification system for agro-healing using an analytic hierarchy process (AHP).

\section{Research Methods}

\section{Hierarchical Criteria Composition and Evaluation Scale}

In this study, the criteria for the classification system were established based on the opinions of experts in related fields. These criteria help to determine the importance of, and prioritize the establishment of, the classification system for Korean agro-healing, referring to the Act on Research, Development and promotion of healing agriculture (2021), Study on methodology and evaluation system of care farming (RDA, 2017), and Korean Standard Industrial Classification (KSIC) (Statistics Korea, 2020). It also involves a value chain system that includes a series of activity processes related to the creation of added value (Porter, 1985). The main criteria consist of three elements including agro-healing input industry, agro-healing service industry, and agro-healing-related (derived) industry; the details of each element are shown in Table 1. Further, there are also 11 sub-criteria, as shown in Table 2. When looking at the sub-criteria for each main criterion, the "agro-healing input industry" is composed of the agro-healing construction industry, agro-healing input manufacturing, crop cultivation and breeding, and the manufacturing of agri-food and related

Table 1. Descriptions of the main criteria

\begin{tabular}{cl}
\hline Main criteria & \multicolumn{1}{c}{ Description } \\
\hline Argo-healing input industry & $\begin{array}{l}\text { As input resources for agro-healing, it consists of argo-healing farm construction, input } \\
\text { material manufacturing, crop cultivation and breeding, and agricultural food and related } \\
\text { processed products manufacturing }\end{array}$ \\
Argo-healing service industry & $\begin{array}{l}\text { As an activity that creates direct added value of agro-healing, it is classified into care } \\
\text { social rehabilitation, and educational healing services according to the type of service }\end{array}$ \\
Argo-healing related or derived industry & $\begin{array}{l}\text { Activities that support the source activities (input, service industry) of argo-healing to } \\
\text { create added value }\end{array}$ \\
\hline
\end{tabular}


Table 2. Descriptions of the sub-criteria

\begin{tabular}{|c|c|c|}
\hline & ub-criteria & Description \\
\hline \multirow{4}{*}{$\begin{array}{l}\text { Argo-healing input } \\
\text { industry }\end{array}$} & $\begin{array}{l}\text { Argo-healing } \\
\text { construction industry }\end{array}$ & $\begin{array}{l}\text { - Agro-healing construction business, related facility construction business } \\
\text { - Improving mobility convenience and facility construction }\end{array}$ \\
\hline & $\begin{array}{l}\text { Agro-healing input } \\
\text { manufacturing }\end{array}$ & $\begin{array}{l}\text { Agro-healing motor operated hand held tool manufacturing, agro-healing machinery } \\
\text { manufacturing } \\
\text { - Tools and machines for the convenience of activities for non-farmers and persons } \\
\text { with limited mobility }\end{array}$ \\
\hline & $\begin{array}{l}\text { Crop cultivation and } \\
\text { breeding }\end{array}$ & $\begin{array}{l}\text { Agro-healing products cultivation, livestock breeding, and pet breeding } \\
\text { - Cultivation and breeding activities provided by the agro-healing farm }\end{array}$ \\
\hline & $\begin{array}{l}\text { Agri-food and related } \\
\text { processed goods } \\
\text { manufacturing }\end{array}$ & $\begin{array}{l}\text { - Agro-healing livestock and agri-food manufacturing } \\
\text { - Horticulture, insect } \\
\text { Other Agro-healing products manufacturing } \\
\text { - Well-being food, processed tea }\end{array}$ \\
\hline \multirow{3}{*}{$\begin{array}{l}\text { Agro-healing } \\
\text { service industry }\end{array}$} & Treatment and rehabilitation & $\begin{array}{l}\text { - Mental rehabilitation treatment } \\
\text { - Intellectual disability, psychological disability, burnout syndrome, autistic patient, } \\
\text { addict } \\
\text { - Physical rehabilitation treatment } \\
\text { - Physical disability, acquired brain disease }\end{array}$ \\
\hline & Social rehabilitation & $\begin{array}{l}\text { Resocialization } \\
\text { - Prison inmates, unemployed person, youth shelter } \\
\text { Education } \\
\text { - Agricultural technology, special education subjects }\end{array}$ \\
\hline & Community service & $\begin{array}{l}\text { - Care service } \\
\text { - Kindergarten, daycare center, elderly with dementia } \\
\text { - Education } \\
\text { - Lifelong education, meditation shelter }\end{array}$ \\
\hline \multirow{4}{*}{$\begin{array}{l}\text { Agro-healing } \\
\text { related } \\
\text { (derived) industry }\end{array}$} & $\begin{array}{l}\text { Training and education } \\
\text { institution for agro-healing } \\
\text { expert }\end{array}$ & $\begin{array}{l}\text { - Agro-healing education service } \\
\text { - Higher education institution, specialized education, and vocational training } \\
\text { institution. }\end{array}$ \\
\hline & $\begin{array}{l}\mathrm{R} \& \mathrm{D} \text { and consulting related } \\
\text { to agro-healing }\end{array}$ & $\begin{array}{l}\text { - Research and development business } \\
\text { - Management consulting business }\end{array}$ \\
\hline & $\begin{array}{l}\text { Industrial and expert } \\
\text { organization related to } \\
\text { agro-healing }\end{array}$ & $\begin{array}{l}\text { - Industrial organization } \\
\text { - Expert organization }\end{array}$ \\
\hline & $\begin{array}{l}\text { Other agro-healing support } \\
\text { service }\end{array}$ & - Promotion of agro-healing \\
\hline
\end{tabular}

processed goods. "Agro-healing service industry" consists of treatment and rehabilitation, social rehabilitation, and community service. Finally, "agro-healing-related/derived industry" is comprised of training and education institutions for agro-healing experts, research and development (R\&D) and consulting services related to agro-healing, industrial and expert organizations related to agro-healing, and other agro-healing support services.

The evaluation scale used for pairwise comparisons is a 9-point scale (Table 3) that includes the reciprocal value proposed by Saaty (1988), which is based on the idea that an average human cannot compare more than 7 objects at the same time $(7 \pm 2)$, as per Miller's (1956) "StimulusResponse" theory. This scale requires $n(n-1) / 2$ comparisons if the immediate lower level consists of $n$ elements (Chung and Yoon, 2008). Pairwise comparisons are performed by assigning scores to the semantic expression (response options) in a survey questionnaire, and the respondent assigns scores to items on the scale that are regarded as relatively more important among two comparators (Lim and Lee, 2019). 
Table 3. Pairwise comparison 9-point scale for Analytic Hierarchy Process preferences

\begin{tabular}{|c|c|c|}
\hline Intensity of importance & Definition & Explanation \\
\hline 1 & Equal importance & To contribute equally to the objective \\
\hline 3 & Moderate importance & Experience or judgment slightly favors one element over another \\
\hline 5 & Strong importance & Experience or judgment strongly favors one element over another \\
\hline 7 & Very strong importance & $\begin{array}{l}\text { One element is favored very strongly over another: its dominance is demonstrated in } \\
\text { practice }\end{array}$ \\
\hline 9 & Extreme importance & Evidence favoring one element over another affirmed to the highest possible order \\
\hline $2,4,6,8$ & Intermediate value & Further subdivision or compromise is needed \\
\hline \multicolumn{2}{|c|}{ Reciprocal of above numbers } & $\begin{array}{l}\text { If an attribute has one of the above numbers assigned to it when compared with a } \\
\text { second attribute, then the second attribute has the reciprocal value when compared } \\
\text { to the first }\end{array}$ \\
\hline
\end{tabular}

\section{Validation Criteria}

Validation of the AHP analysis can be confirmed through a consistency ratio (CR), which is a value obtained by dividing the consistency index (CI) by the average of the random index (RI; Vaidya and Kumar, 2004). In general, the smaller the $\mathrm{CR}$ value, the greater the consistency of the judgment (decision making); with respect to the criterion, if the value is less than $0.2(20 \%)$, then it may be that the respondent makes judgments with some consistency (Lee, 2007; Park, 2012). If the CR value is 0.2 or greater, it is regarded as inconsistent (Vaidya and Kumar, 2004) and re-survey is recommended.

Three or four experts participated in the existing AHP analysis. However, a limitation was raised as far as the overall decision-making process may be distorted by motivational bias due to the small number of participants. Thus, KDI (2008) established guidelines for deriving the results of the AHP analysis by increasing the number of experts to 7 or 8 . As such, the AHP analysis is primarily used in decision-making processes that require expertise. Unlike general survey methods, this approach helps to obtain significant decision-making results with a small sample. Therefore, it is important to consider which expert group in the relevant field is selected as a participant, and how faithfully and consistently the participants responded (Saaty, 2008; Kim et al, 2007).

\section{Subjects and Data Collection}

From October 21 to October 30, 2021, a survey was administered to 79 students and faculty at 6 educational institutions that foster agro-healing specialists. These respondents comprised a group of experts with at least 5 years of experience in agro-healing and related industries, and who were currently operating healing farms (rural or urban) or working at agro-healing education institutions including hospitals, clinics, and private medical institutions; private institutions such as welfare centers; horticultural therapy associations; and universities.

As a result of measuring the individual CR for 79 response sheets, it was found that the $\mathrm{CR}$ of 61 response sheets exceeded 0.2 , rendering them unsuitable for analysis. According to Hong (2011), the AHP technique is performed using pairwise comparisons of survey responses, which are respondents' subjective judgments. When comparing the relative weights between evaluated factors, if a pair of items is not evaluated as $\mathrm{A}>\mathrm{C}$ and is instead evaluated as $\mathrm{C}>\mathrm{A}$ when $\mathrm{A}>\mathrm{B}$ and $\mathrm{B}<\mathrm{C}$ in the degree of relative weights, the response lacks consistency, which indicates a lack of reliability. Therefore, these comparisons are related to the quality of the evaluation. In this study, when considering these validation criteria, 18 responses with $\mathrm{CR}<0.2$ (Saaty, 1990) were selected for the final analysis, as they were reflective of the fact that the evaluation was performed with an acceptable level of consistency.

\section{Analysis Method}

An analysis of demographic data was performed using SPSS 25.0 (IBM, USA) for the final selected responses. Then, the AHP analysis to establish the classification sys- 


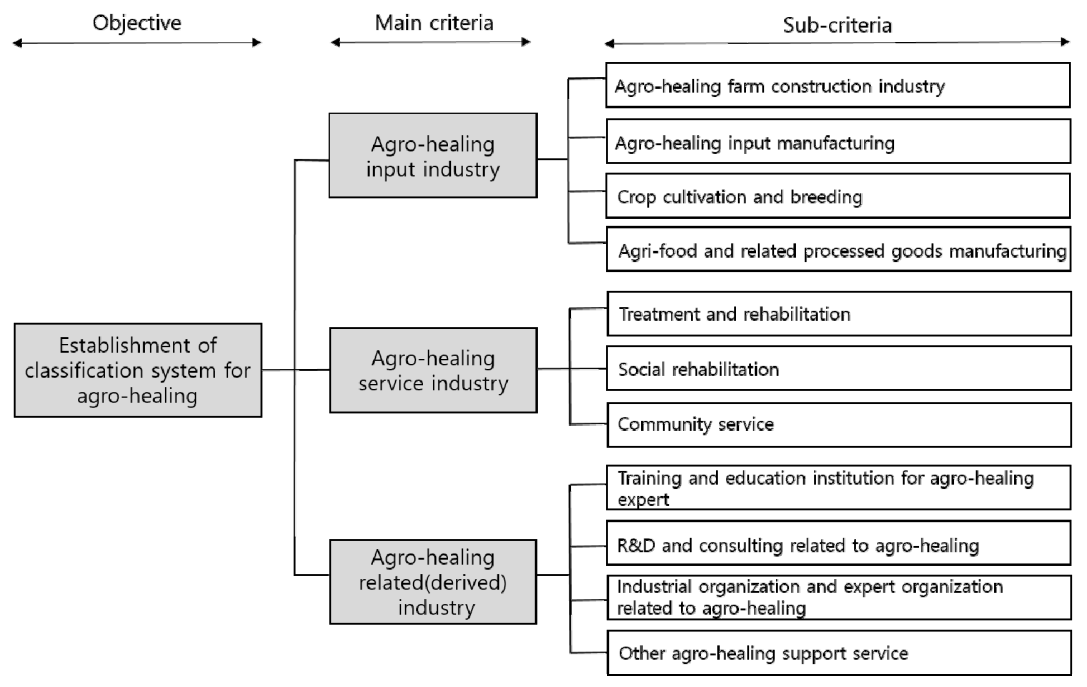

Fig. 1. Hierarchical structure of the classification system.

tem for agro-healing was performed using DRESS 1.3 (CHOISH, KOREA), an AHP analysis software package that is capable of analyzing the importance (weights) and priority level of the hierarchical structure of this study (Fig. 1). Since AHP analysis is a technique that can be used to select an optimal alternative by classifying multiple attributes hierarchically and performing pairwise comparisons on the importance of each attribute, it is used as a decision-making tool that enables rational choices of respondents by presenting complex problems in a simple and systematic manner (Lee, 2011; Saaty, 1990).

\section{Results and Discussion}

\section{General Characteristics of Survey Respondents}

The demographic characteristics of the respondents are presented in Table 4. There were 8 males (44.4\%) and 10 females $(55.6 \%)$; respondents were most commonly in their $50 \mathrm{~s}(\mathrm{n}=13 ; 72.7 \%)$ or $40 \mathrm{~s}(\mathrm{n}=3 ; 16.7 \%)$, and there was 1 person each $(5.6 \%)$ in their $30 \mathrm{~s}$ and in their $60 \mathrm{~s}$. With respect to respondents' careers in agro-healing and related industries, most $(\mathrm{n}=11 ; 61.1 \%)$ had 5 to 10 years of experience, while some $(\mathrm{n}=4 ; 22.2 \%)$ had 15 or more years of experience, and a few $(\mathrm{n}=3 ; 16.7 \%)$ had 10 to 15 years of experience. In terms of their current workplace, respondents were able to provide multiple responses; par- ticipants most commonly worked in educational institutions such as universities (33.3\%), followed by private institutions such as horticultural treatment associations (14.8\%) and welfare centers (11.1\%); urban agro-healing farms $(11.1 \%)$; plant production (11.1\%); rural agro-healing farms (7.4\%); hospitals, clinics, and private medical institutions (3.7\%); and as agro-healing activists (3.7\%).

\section{AHP Analysis}

The results from the analysis of the relative weights and priority levels of the main criteria and sub-criteria for the agro-healing classification system are shown in Table 5. With respect to the main criteria, the agro-healing service industry ( 0.52$)$ showed the highest weight, followed by the agro-healing related (derived) industry $(0.32)$ and agrohealing input industry (0.16). The CR for the main criteria was found to be 0.00 , indicating that respondents provided consistent responses, as identified during the pairwise comparison.

The weights and priority levels for the sub-criteria are as follows: In the agro-healing input industry, the $\mathrm{CR}$ for the sub-criteria was found to be 0.01 , while crop cultivation and breeding (0.42) showed the highest weight, followed by the manufacturing of agri-food and related processed goods (0.32), the agro-healing construction industry (0.13), and agro-healing input manufacturing (0.13). In the agrohealing service industry, the $\mathrm{CR}$ for the sub-criteria was 
Table 4. Characteristic of survey respondents

$(N=18)$

\begin{tabular}{|c|c|c|c|c|c|}
\hline Variable & Categories & Frequency $(\%)$ & Variable & Categories & Frequency $(\%)$ \\
\hline \multirow{2}{*}{ Gender } & Male & $8(44.4)$ & \multirow{14}{*}{ Place of work ${ }^{*}$} & Rural agro-healing farm & $2(7.4)$ \\
\hline & Female & $10(55.6)$ & & Urban agro-healing farm & $3(11.1)$ \\
\hline \multirow{5}{*}{ Age } & $20 \mathrm{~s}$ & 0 & & Plant production & $3(11.1)$ \\
\hline & $30 \mathrm{~s}$ & $1(5.6)$ & & Stock breeding & $1(3.7)$ \\
\hline & $40 \mathrm{~s}$ & $3(16.7)$ & & Hospitals, clinics , and private medical institutions & $1(3.7)$ \\
\hline & $50 \mathrm{~s}$ & $13(72.2)$ & & $\begin{array}{l}\text { Government medical institutions such as public } \\
\text { health centers }\end{array}$ & 0 \\
\hline & 60 or over & $1(5.6)$ & & Private institutions such as welfare centers & $3(11.1)$ \\
\hline \multirow{3}{*}{ Education } & University & $9(50.0)$ & & $\begin{array}{l}\text { Government institutions such as administration } \\
\text { and research }\end{array}$ & 0 \\
\hline & Graduate school (M.D.) & $1(5.6)$ & & $\begin{array}{c}\text { Private institutions such as the Horticultural } \\
\text { Therapy Association }\end{array}$ & $4(14.8)$ \\
\hline & Graduate school (Ph.D.) & $8(44.4)$ & & Private healing institution & 0 \\
\hline \multirow{4}{*}{$\begin{array}{l}\text { Work } \\
\text { experience }\end{array}$} & Less than 5 years & 0 & & Protective custody office & 0 \\
\hline & $5-10$ years & $11(61.1)$ & & Educational institutions such as universities & $9(33.3)$ \\
\hline & $10-15$ years & $3(16.7)$ & & Activists & $1(3.7)$ \\
\hline & More than 15 years & $4(22.2)$ & & Other & 0 \\
\hline
\end{tabular}

Multiple response options.

Table 5. Pairwise comparison matrix for the criteria using AHP.

\begin{tabular}{|c|c|c|c|c|c|c|c|}
\hline Main criteria & $\mathrm{CR}^{\mathrm{z}}$ & Weight & Priority & Sub-criteria & $\mathrm{CR}$ & Weight & Priority \\
\hline \multirow{4}{*}{$\begin{array}{l}\text { Agro-healing } \\
\text { input industry }\end{array}$} & \multirow{4}{*}{0.00} & \multirow{4}{*}{0.16} & \multirow{4}{*}{3} & Agro-healing construction industry & \multirow{4}{*}{0.01} & 0.13 & 3 \\
\hline & & & & Agro-healing input manufacturing & & 0.13 & 3 \\
\hline & & & & Crop cultivation and breeding & & 0.42 & 1 \\
\hline & & & & Manufacturing of agri-food and related processed goods & & 0.32 & 2 \\
\hline \multirow{3}{*}{$\begin{array}{l}\text { Agro-healing } \\
\text { service industry }\end{array}$} & \multirow{3}{*}{0.00} & \multirow{3}{*}{0.52} & \multirow{3}{*}{1} & Treatment and rehabilitation & \multirow{3}{*}{0.00} & 0.23 & 3 \\
\hline & & & & Social rehabilitation & & 0.30 & 2 \\
\hline & & & & Community service & & 0.47 & 1 \\
\hline \multirow{4}{*}{$\begin{array}{l}\text { Agro-healing- } \\
\text { related/derived } \\
\text { industry }\end{array}$} & \multirow{4}{*}{0.00} & \multirow{4}{*}{0.32} & \multirow{4}{*}{2} & $\begin{array}{l}\text { Training and education institutions for agro-healing } \\
\text { experts }\end{array}$ & \multirow{4}{*}{0.00} & 0.28 & 2 \\
\hline & & & & R\&D and consulting related to agro-healing & & 0.20 & 3 \\
\hline & & & & $\begin{array}{l}\text { Industrial and expert organizations related to } \\
\text { agro-healing }\end{array}$ & & 0.18 & 4 \\
\hline & & & & Other agro-healing support services & & 0.33 & 1 \\
\hline
\end{tabular}

${ }^{\mathrm{z}}$ Consistency ratio.

0.00 , and the weight was the highest for community service $(0.47)$, followed by social rehabilitation $(0.30)$, and treatment and rehabilitation (0.23). In the agro-healing- related/derived industry, the $\mathrm{CR}$ for the sub-criteria was 0.00 , indicating response consistency. Other agro-healing support services $(0.33)$ had the highest weight, followed by training and education institutions for agro-healing experts (0.28),
R\&D and consulting related to agro-healing (0.20), and industrial and expert organizations related to agro-healing (0.18).

Complex weights were calculated based on the analysis results to determine the priority level of all evaluation items for establishing the agro-healing classification system (Table 6). These weights were obtained using a general 
Table 6. The AHP criteria ranking and their complex weights.

\begin{tabular}{clcc}
\hline $\begin{array}{c}\text { Overall } \\
\text { priority }\end{array}$ & \multicolumn{1}{c}{ Sub-criteria } & $\begin{array}{c}\text { Complex } \\
\text { weight }\end{array}$ & Main criteria \\
\hline 1 & Community service & 0.2411 & Agro-healing service industry \\
2 & Social rehabilitation & 0.1574 & Agro-healing service industry \\
3 & Treatment and rehabilitation & 0.1197 & Agro-healing service industry \\
4 & Other agro-healing support services & 0.1064 & Agro-healing-related/derived industry \\
5 & Training and education institutions for agro-healing experts & 0.0901 & Agro-healing-related/derived industry \\
6 & Crop cultivation and breeding & 0.0675 & Agro-healing input industry \\
7 & R\&D and consulting related to agro-healing & 0.0650 & Agro-healing-related/derived industry \\
8 & Industrial and expert organizations related to agro-healing & 0.0582 & Agro-healing-related/derived industry \\
9 & Manufacturing of agri-food and related processed goods & 0.0526 & Agro-healing input industry \\
10 & Agro-healing construction industry & 0.0210 & Agro-healing input industry \\
10 & Agro-healing input manufacturing & 0.0210 & Agro-healing input industry \\
\hline
\end{tabular}

method that is often used to calculate relative weights, in which the weight of each evaluation item of the main criteria was calculated using the AHP (pairwise comparison), and the value was multiplied by the weight of each evaluation item of the sub-criteria (Lee at al., 2017).

Of the 11 sub-criteria, community service $(0.2411)$ had the highest complex weight, followed by social rehabilitation (0.1574), treatment and rehabilitation (0.1197), other agro-healing support services (0.1064), training and education institutions for agro-healing experts (0.0901), crop cultivation and breeding (0.0675), R\&D and consulting related to agro-healing (0.0650), industrial and expert organizations related to agro-healing (0.0582), and manufacturing of agri-food and related processed goods (0.0526). The agro-healing construction industry (0.0210) and agro-healing input manufacturing (0.0210) criteria were found to have the lowest complex weights.

When examining the above analysis findings, which were grouped based on sub-criteria per main criterion, all three items (community service, which featured the highest complex weight; social rehabilitation, which ranked 2nd; and treatment and rehabilitation, which ranked 3rd) fell within "agro-healing service industry" as the main criterion. Jeong et al. (2020) reported that anyone can become a target of agro-healing, even if they do not have specific physical or emotional problems, and that there should be widespread awareness that anyone can experience agro-healing activities. This is in line with the fact that community serv- ice showed the highest complex weight among the 11 sub-criteria. Community services - providing care services for nursery schools, daycare centers, and the elderly with dementia, as well as education-related services for the general public, such as lifelong education and meditation shelters - represent the most important factor to be considered when creating an agro-healing classification system. In addition, the identification of social rehabilitation, and treatment and rehabilitation as high-priority factors suggests that the agro-healing system and its associated activities should be established and developed with a focus on the importance and role of agro-healing activities (RDA, 2016). This is important, as these activities can focus on healing those who are under work-related stress or poor health, as well as those in need of medical and social treatment (such as those living with mental illness, depression, learning disabilities, substance misuse, and those with social dissatisfaction).

For complex weights of sub-criteria that fall under the main criterion of "agro-healing-related/derived industry," other agro-healing support services ranked 4th, training and education institutions for agro-healing experts ranked 5th, R\&D and consulting related to agro-healing ranked 7 th, and industrial and expert organizations related to agro-healing ranked 8th; indicating an intermediate level of weights among the three main criteria. This finding is considered to reflect experts' opinions on the need for a classification system for the service industry, which is in charge of public 
relations to establish and activate agro-healing, as well as agro-healing related/derived industry as support activities that foster the development of agro-healing experts through the provision of training and education institutions. As interest in agro-healing farms and agro-healing increased after the Act on Research, Development and Promotion of Healing Agriculture came into effect, the need for both information on agro-healing activities at agro-healing farms and research on its effects has frequently been raised (Jang et al., 2020). In this context, the segmentation and organic linkage of agro-healing-related support services, expert training and education institutions, and R\&D and consulting are required for agro-healing activity support and in-depth research to confirm its effects.

For the sub-criteria of "agro-healing input industry", crop cultivation and breeding ranked 6th, the manufacturing of agri-food and related processed goods ranked 9th, and the agro-healing construction industry and agro-healing input manufacturing tied for 10th, showing the lowest weights. This means that research exploring agro-healing construction industry and agro-healing input manufacturing awareness and systems should be promoted. Crop cultivation and breeding was found to be the most important factor among the four sub-criteria for the agro-healing input industry. This finding may have resulted from the fact that horticultural crops and livestock-raising activities provided by agro-healing farms are directly related to agro-healing services, which is an essential element underlying all agro-healing activities.

\section{Conclusion}

In this study, after determining the priority levels of the agro-healing classification system, the AHP analysis was performed on the survey results of 18 agro-healing experts to provide the basic data needed to set policy directions for the establishment and vitalization of healing agriculture, and the development of the agro-healing industry. Based on the results of this study, the priorities of the agro-healing classification system are summarized as follows.

First, community services $(0.2411)$ showed the highest complex weight, followed by social rehabilitation (0.1574), which ranked 2nd, and treatment and rehabilitation (0.1197), which ranked 3rd, all of which were found to be sub-criteria from the main criterion, "agro-healing service industry." This finding suggests that the criterion that needs to be reviewed first to establish the classification system is the agro-healing service industry. Therefore, research on agro-healing service classification system based on considerable expertise and verified results should be continued in connection with social purpose services.

Second, the sub-criteria corresponding to the main criteria, "agro-healing related (derived) industry", showed the following complex weights: other agro-healing support service $(0.1064)$ ranked 4th, training and education institutions for agro-healing experts (0.0901) ranked 5th, $\mathrm{R} \& \mathrm{D}$ and consulting related to agro-healing (0.0650) ranked 7th, and industrial and expert organizations related to agro-healing (0.0582) ranked 8th. These results indicate that a detailed classification system of agro-healing should be established by creating various related/derived industries that secure expertise in agro-healing-related personnel, research, and organizations.

Third, among the sub-criteria for "agro-healing input industry," crop cultivation and breeding (0.0675) ranked 6th, and agro-healing construction industry (0.0210) and agro-healing input manufacturing $(0.0210)$ both were ranked equally at 10 th, showing the lowest complex weight of the 11 sub-criteria. These results suggest that a more in-depth analysis and re-examination of the input industry as an agro-healing activity should be need and considered.

This study identified the priorities needed to establish the agro-healing classification system is expected to be utilized as basic data that can contribute to the research and development of related industries for the expansion of agro-healing activities and applications. However, this study has several limitations. First, the CR was set at 0.2 , which was considered to be indicative of some degree of consistency. If the CR threshold was set at 0.1 or less, the results may have strictly excluded respondents' subjectivity. In addition, a more in-depth analysis would have been possible if the evaluation ability of respondents who were unfamiliar with the survey questions used for the pairwise comparison was first determine and guided examples were presented. 
Second, this study has some degree of bias towards the experts, as the expert group recruited from the treatment and rehabilitation and social rehabilitation fields for the final analysis was fairly homogeneous. In future follow-up studies, it is necessary to recruit and further classify members from more diverse expert groups, such as those involved in public medical institutions like public health centers, and social protection centers, and to collect opinions based on specific areas of expertise. Such research is expected to be helpful in securing expertise to develop the classification system for agro-healing in Korea, which combines the concepts of healing and treatment, and is revitalizing agro-healing activities.

\section{References}

Chung, J.Y. and T.K. Yoon. 2008. A study on the preference analysis of apartment purchaser using AHP method. J. Korea Inst. Build. Constr. 8(3):51-58. http://2015. jkibc.org/Upload/files/JKIBC/080301.pdf

Garcia-Llorente, M., R. Rubio-Olivar, and I. GutierrezBriceno. 2018. Farming for life quality and sustainability: A literature review of green care research trends in Europe. Int. J. Environ. Res. Public Health 15(6): 1282. https://doi.org/10.3390/ijerph15061282

Healing Agriculture Research and Development and Promotion Act No. 17100. 2021. Retrieved from https://www.law. go.kr/\%EB\%B2\%95\%EB\%A0\%B9/\%EC\%B9\%98\%E C\%9C\%A0\%EB\%86\%8D\%EC\%97\%85\%EC\%97\%B0

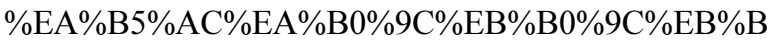
$0 \% 8 \mathrm{~F} \% \mathrm{EC} \% 9 \mathrm{C} \% \mathrm{~A} 1 \% \mathrm{EC} \% 84 \% \mathrm{~B} 1 \% \mathrm{EC} \% 97 \% 90 \% \mathrm{EA}$ $\%$ B4\%80\%ED\%95\%9C\%EB\%B2\%95\%EB\%A5\%A0/( 17100)

Hong, J.M. 2011. An AHP approach for the importance weight of renewable energy investment criterion in the private sector. Korean Energy Econ. Rev. 10(1):115142.

Hong, J.Y. and B.O. Lee. 2016. Analysis of policy priorities for training agro-healing experts using the AHP method. J. Agric. Ext. Community Dev. 23(4): 419-429. https://doi.org 10.12653/jecd.2016.23.4.0419

Jang, H.S., S.J. Jeong, J.S. Kim, and E.H. Yoo. 2020. Relationship between participants satisfaction in agro- healing activities in a healing farm and the level of stress and loyalty. J. People Plants Environ. 23(4):411-422. https://doi.org/10.11628/ksppe.2020.23.4.411

Jang, J.H., S.Y. Jung, H.Y. Kang, E.S. Lim, J.I. Lee, and S.M. Lee. 2021. SA study on agro-healing as a tourism resource healing experience tourism resources. J. Korean Soc. Rural Tour. 24(1): 111-118.

Jeong, S.J., E.H. Yoo, J.S. Kim, H.S. Jang, and G.W. Lee. 2020. Analysis of 2010s research trends in research on agro-healing in South Korea. J. People Plants Environ. 23(3): 267-276. https://doi.org/10.11628/ksppe.2020.23.3.267

Jo, W.J. 2021. A plan to build a village-type rural healing tourism model in Jeollabuk-do. [Jthink] Issue Briefing 245:1-12. Retrieved from http://www.jthink.kr/jthink/ 2018/inner.php?sMenu $=$ B1000\&mode $=$ view \&no $=327$

Korea Development Institute (KDI). 2008. Revision and supplementary study of general guidelines for conducting preliminary feasibility study (5th edition). Instr. Res. 2008:1-455. Retrieved from https://www.kdi.re.kr/research/subjects_view.jsp?pub_no $=11672$

Kim, D.G., Y.W. Park, and S.M. Lee. 2007. Assessment of tourism resource development by the analytic hierarchy process : Focusing on the planning process. Int. J. Tour. Hosp. Res. 21(4):5-18.

Kim, K.M., J.H. Moon, S.J. Jung, and S.M. Lee. 2013. Analysis on the present status and characteristics of agro-healing in Korea. J. Agric. Ext. Community Dev. 23(4):419-429. https://doi.org/10.12653/jecd.2013.20.4. 0909

Lee, J.D., Y. Kim, and S.S. Hong. 2017. A study on the development of assessment index for urban regeneration project using AHP. J. Resid. Environ. Inst. Korea 15(3):333-348. http://doi.org/10.22313/reik.2017.15.3.333

Lee, J.M. 2011. Derivation of HRD policy direction in the field of green technology using AHP methodology. J. Korea Contents Assoc. 11(6):350-359. http://dx.doi. org/10.5392/JKCA.2011.11.6.350

Lee, J.S. 2007. A study on the selection of Hotel utilized AHP. J. Tour. Leis. Res. 19(3):167-186.

Lee, Y.J. 2016. Social agriculture in the Netherlands: Focusing on care farming. Korea Rural Economic Institute. World Agric. 195:31-47. Retrieved from https:// www.krei.re.kr/krei/researchReportView.do?key $=308 \&$ pageType $=0301 \&$ biblioId $=396991$ 
Lim, J.H. and B.K. Lee. 2019. An analysis on priority of school library evaluation index utilizing the AHP. J. Korean Libr. Inf. Sci. Soc. 50(2):169-189. http://doi.org/10.16981/kliss.50.2.201906.169

Miller, G.A. 1956. The magical number seven plus or minus Two: Some limits on our capacity for processing information. Psychol. Rev. 63(2):81-97.

Oh, S.J. 2020. The re-examination on the concept of healing by Ken Wilber's integral frameworks. J. Nat. Heal. 4(2):39-52. https://doi.org/10.12972/jnh.20200004

Park, H.C. and D.G. Kang. 2017. Suggestions for applications of therapeutic farms for promoting school community engagement in Korea based on review of therapeutic farms, gardens, animals, policies, and laws in the U.S.A. J. Rural. Soc. 27(2):215-269. http://doi.org/10.31894/JRS.2017.12.27.2.215

Park, J.D. 2012. Analysis of relative importance and priority of civil servant's education training policy: Using Analytic Hierarchy Process (AHP) method. J. Korea Contents Assoc.. 12(4):263-272. https://doi.org/10.5392/ JKCA.2012.12.04.263

Porter, M.E. 1985. Competitive Advantage: Creating and Sustaining Superior Performance (pp. 33-61). New York: Free Press. Retrieved from https://www.hbs.edu/faculty/Pages/item.aspx?num=193

Rural Development Administration (RDA). 2016. Understanding of agro-healing (care farming). pp. 1-95. Retrieved from https://lib.rda.go.kr/search/mediaView.do?mets_no $=000$ 000187083

Rural Development Administration (RDA). 2017. Study on methodology and evaluation system of care farming. pp. 1-161. https://doi.org/10.23000/TRKO201700006439

Rural Development Administration (RDA). 2020. Agrohealing. Agricultural Technology Guide 222. pp. 1-170. Retrieved from https://lib.rda.go.kr/search/mediaView. do?mets_no $=000000312322$

Saaty, T.L. 1988. What is the analytic hierarchy process? In Mathematical models for decision support. Springer, Berlin, Germany. 48:109-121. https://doi.org/10.1007/ 978-3-642-83555-1_5

Saaty, T.L. 1990. How to make a decision: the analytic hierarchy process. Eur. J. Oper. Res. 48(1):9-26. https:// doi.org/10.1016/0377-2217(90)90057-I

Saaty, T.L. 2008. Relative measurement and its generalization in decision making why pairwise comparisons are central in mathematics for the measurement of intangible factors the analytic hierarchy/network process. RACSAM-Revista de la Real Academia de Ciencias Exactas, Fisicas y Naturales. Serie A. Matematicas 102(2):251-318. Retrieved from https://link.springer. com/article/10.1007/BF03191825

Statistics Korea. 2020. Korea Standard Industry Code. Retrieved from http://kssc.kostat.go.kr/ksscNew_web/ link.do?gubun $=001$

Vaidya, O.S. and S.S. Kumar. 2004. Analytic hierarchy process: An overview of applications. Eur. J. Oper. Res. 169:1-29. https://doi.org/10.1016/j.ejor.2004.04.028

WHO. 1948. Constitution of World Health Organization (April 7, 1948). Geneva. Retrieved from Constitution of the World Health Organization (who.int). 